\title{
Characteristics of Methodology of Teaching and Training Teen-Age Sambo Wrestlers
}

\author{
Igoshin V.Yu. \\ I. Ya. Yakovlev State Pedagogical University \\ Cheboksary, Russia \\ valera.igoshin.61@mail.ru
}

\author{
Igoshina N.V. \\ I. Ya. Yakovlev State Pedagogical University \\ Cheboksary, Russia \\ valera.igoshin.61@mail.ru
}

\author{
Antonova T.V. \\ I. Ya. Yakovlev State Pedagogical University \\ Cheboksary, Russia \\ valera.igoshin.61@mail.ru
}

\begin{abstract}
The article presents results of the methodology of teaching and training teen-age sambo wrestlers. Sambo in Russia has received great development and has become one of the favorite sports of teenagers. We have made innovative changes to the traditional methodology physical qualities development Sambo wrestlers, providing a more specialized impact on the development of these qualities. The problem of the study is to determine the features of the methodology of training, causing a significant increase in the efficiency of the development of physical qualities in Sambo athletes in adolescence. Data analysis was carried out in 24 subjects aged 14-15 years, constituting the control and experimental groups. The training process in both groups of subjects was organized taking into account the requirements of the approximate program of sports training for children's and youth sports schools, specialized children's and youth sports schools of the Olympic reserve, developed by $\mathbf{S}$. E. Tabakov, C. B. Eliseev and B. Konakov. The experimental method of development of physical qualities of Sambo wrestlers of teenage age included a number of innovative changes in development: power qualities, special endurance, dexterity, flexibility. Comparative analysis of physical fitness indicators observed after the completion of the pedagogical experiment showed that the Sambo athletes of the experimental group had significantly better results in test exercises characterizing the level of general endurance development, speed-strength and strength qualities. They are distinguished by higher performance in the women's $3,000 \mathrm{~m}$, they observed significantly better results in the long jump with the pull-UPS from hang in push-in push-up position, the tray legs to the bar of the vis in the bench press. We believe that we observed after the completion of the pedagogical experiment significant advantage Sambo experimental group in terms of overall endurance, speed-strength and strength qualities and due to the use of physical training developed by us innovative methods of physical qualities development.
\end{abstract}

Keywords-sambo; teen-agers; methodology of teaching and training.

\section{INTRODUCTION}

In the law of the Russian Federation "On physical culture and sport in the Russian Federation", in the Strategy of physical culture and sport development in the Russian Federation for the period till 2020, adopted by the order of the Russian Federation Government on August,7, 2009 №1101-r, one of strategic objectives of society and state in the sphere of physical culture and sport a successful participation of Russian athletes in important International competitions is defined the Olympic Games, World Cups, World Championships and Europe Championships.

A leading role in prestigious function of sport realization belongs to those kinds of sport, which are included into the program of International competitions, including sambo.

\section{LITERATURE REVIEW}

Sambo is very popular in our country and became one of the most favorite kinds of sport among youth. Thousands of young men and adults regularly go in for sambo, develop their mastery in sports schools for teen-agers and youth, in sections of physical culture collectives. During recent years there were some changes in sambo development. More and more people start going in for this kind of sport. The training staff also increases, not only its amount increases, but also coaches' professional mastery and the level of teaching. Coaches gained professional experience of training outstanding sambo wrestlers, both in this country and abroad, material opportunities also improved. Changes also happened in the rules of competitions. The number of competitions inside the country and abroad increases constantly. All these moments influenced directly the methodology of training sambo wrestlers of all categories, both beginners and masters. New educational and educational-methodical manuals concerning sambo wrestlers' special physical qualities, technique, tactics and psychological training development were published (A. V. Eganov, 2008; A. P. Kuptsov, 1978; A. N. Lents, 1964; R. A. Piloyan, 1999; D.L. Rudman. 1995; A. G. Stankov, 1995; G. S. Tumanyan, 2006 and others). Sports training model sambo program for sports schools for children and teen-agers, sports schools of the Olympic reserve was created and adopted under 
the edition of Tabakov S.E., Eliseev S.V., Konakov V. (2005). Theoretical and methodical basis of motor actions teaching process development were considered in the works of N. A. Bernshtein (1991), M. M. Bogen (1985), L. P. Matveev (2005), V. N. Platonov (1986) and others. In the work of A.A. Karelin (2002) the problem of a rational succession of sports wrestling techniques teaching is considered. V.F. Kostychakov (2006) created and scientifically substantiated playing technology of sambo wrestlers' educational-training process activation. In the work of R.A. Layshev (1997) the methodology of movements coordination development among children, who go in for sambo, is presented. The peculiarities of coordinating abilities development among wrestlers were studied by A.V. Melchakov (2004). V.V. Romanov (2006) studied the methodology of sports selection of sambo wrestlers at educational-training stage. R.M. Gorodnichev (2001) considered physiological basis of sambo wrestlers teaching and training development. A.G. Stankov (1995) studied the approaches to sports training individualization in different kinds of sports wrestling, including sambo. In general, scientific-methodical literature analysis and summarizing proves that the separate aspects of sambo wrestlers' sports training improvement were studied by many scientists. At the same time, the questions of teaching and training teen-agers sambo wrestlers are not studied enough.

\section{RESEARCH METHODOLOGY}

Thus, we can say about contradiction between considerable importance of a high level of physical readiness and mastering the ways of techniques fulfillment for the effectiveness of competitive activity increase in sambo, on the one hand, and on the other hand, insufficient scientific substantiation of teaching and training methodology among young sambo wrestlers during teen-age period. The necessity to overcome this contradiction conditions the urgency of our research work. The problem of the research: what are the peculiarities of the methodology of teaching and training, which condition considerable effectiveness increase of physical qualities development among sambo wrestlers during teen-age period? The object of the research - sports training of sambo wrestlers. The subject of the research - the process of teaching and training sambo wrestlers at teen-age period. In accordance with the content of the problem the aim of our research work was in means and methods determination of teaching and training teenage sambo wrestlers, which condition considerable effectiveness increase of physical qualities development process. Hypothesis of the research. Physical training effectiveness increase among teen-age sambo wrestlers is possible, if the used training means and methods would correspond with age related morphological-functional organism peculiarities of those, who train. In order to achieve the aim of the research, taking into account the theses of the hypothesis, we solved the following objectives:

1. To characterize sambo as a kind of sport and the means of physical upbringing.

2. To analyze training means and methods, used in teaching and training sambo wrestlers.

3. To create and experimentally substantiate the methodology of physical training among teenage sambo wrestlers, which provides physical qualities development improvement.

In order to solve the objectives of the research we used the following research methods: scientific-methodical literature theoretical analysis and summarizing, pedagogical testing, pedagogical experiment, methods of mathematical statistics.

The research included 4 stages.

At the first stage (September, 2018) we revealed theoretical and methodical basis of the research problem solution on the basis of scientific-methodical literature theoretical analysis. We substantiated urgency of the studied problem, formulated contradictions, problems, the object and aim of the research, created theses of the hypothesis and defined specific objectives.

At the second stage (October-November, 2018) we introduced innovative changes into traditional methodology of physical training of sambo wrestlers on the basis of scientificmethodical literature analysis and summarizing. These changes took into account the content specificity of this kind of wrestling and age related peculiarities of 12-14 year-old teen-agers' organism and personality.

At the third stage (December, 2018-March 2019) we carried out a pedagogical experiment, directed toward practical substantiation of the experimental methodology effectiveness in educational-training process of sambo wrestlers.

At the $4^{\text {th }}$ stage (April-May, 2019) we realized content (qualitative) and quantitative analysis of experimental work materials.

The aim of the experimental work was to create and scientifically substantiate the methodology of physical training of teenage sambo wrestlers.

In order to achieve this aim the following specific objectives were considered:

1. To create the methodology of sambo wrestlers' physical qualities development.

2. To substantiate experimentally the effectiveness of this methodology use in physical training of teenage sambo wrestlers.

Sambo is self-defense without any weapon - is the kind of wrestling in clothes. The place of combat is a wrestling mat, regulations of competitions and weight categories are the same as in Greco-Roman and freestyle wrestling. In sambo permitted in judo holds are used, apart from suffocating one. Also pain hands and legs techniques, legs hold, legs techniques are used: trips, reapings, ankle trips and others. The victory is gained by a person who fulfills a back throw, remains standing and for pain technique during lying position combat. In other cases the victory is gained according to the points.

\section{RESULTS}

The experimental methodology of physical qualities development among teenage sambo wrestlers included several 
innovative changes.

\section{In strength oriented qualities development:}

- the amount of exercises with great poundage was decreased with simultaneous increase of exercises with the average weight poundage, fulfilled in speed regime in terms of dynamic efforts method;

- $\quad$ exercises for power of prelum abdominale muscles development were fulfilled with the efforts, which didn't cause great straining;

- $\quad$ during strength oriented exercises fulfillment special attention was paid to deep breathing teaching through the nose, with moderate frequency and without breath holding;

- the amount of strength oriented exercises, which correspond with the character of the efforts, developed during wrestling techniques fulfillment, in terms of their biodynamic structure is increased.

In special endurance development the part of specialized exercises was increased (educational-training combats in the average tempo during 5 minutes). The training load increase was provided owing to gradual rest intervals decrease and the duration of exercises fulfillment and the tempo of combat conduct increase.

In dexterity development the part of specialized exercises, which demand quick movements and motor actions transformation in accordance with the changing conditions of activity, was increased.

In flexibility development the relative volume of activepassive exercises and the exercises with the average poundage was increase. These exercises demanded high level of activity in joints.

Two groups of respondents, who go in for sambo, took part in the pedagogical experiment.

The control group included 12 people at the age of 14-15, the experimental group included 12 people of the same age.

The experiment was held on the basis of autonomous establishment "Sambo and Judo Sports school of the Olympic reserve №10" since December, 1, 2018 till March, 31, 2019 and included 4 training mesocycles.

Educational-training process in both groups of respondents was organized taking into account the demands of the model program of sports training for children and teen-agers sports schools, specialized children and teen-agers sports schools of the Olympic reserve, created by S.E. Tabakov, S.V. Eliseev and V. Konakov [12].

The methodology of physical training in the experimental group included innovative changes, the content of which was described by us above.

At the beginning and at the end of the pedagogical experiment we measured physical qualities indices of the respondents from both groups.

The level of speed qualities development was estimated according to the results of two test exercises fulfillment:
- $\quad 30$ meters running from high start. The best result in seconds from two attempts was taken into account;

- 100 meters running from high start. The time of running the part of the distance in seconds was taken into account.

The level of general endurance development was estimated according to the results of 3000 meters running.

The level of speed-power oriented qualities development was estimated according to the results in standing jump.

The level of strength oriented qualities development was estimated according to the results of the following testing exercises fulfillment:

- $\quad$ chin-up from hanging position, quantity; dip-up in lying position, quantity; legs bringing to the bar from hanging position, quantity; benchpress. The weight of the barbell in $\mathrm{kg}$ was taken into consideration.

The results of the research are presented in tables I-II.

It was stated that at the beginning of the forming pedagogical experiment physical qualities indices among the respondents from the control and experimental groups didn't differ much (table 1).

Almost the same were the results in the following test exercises: 30 meters running (5,04 and 4,99 seconds), 100 meters running (15,04 and 14,98 seconds), 3000 meters running (795,4 and 793,2 seconds), standing long jump (188,6 and $185,1 \mathrm{~cm})$, chin-ups from the hanging position $(10,6$ and 10,9 quantity), push-ups

(48,7 and 45,2 times), legs bringing to the barbell from hanging position ( 10,2 and 9,9 times) and benchpress (54,6 and $53,2 \mathrm{~kg}$ ).

TABLE I. PHYSICAL READINESS INDICES AMONG SAMBO WRESTLERS AT THE BEGINNING OF THE FORMING PEDAGOGICAL EXPERIMENT, $(\mathrm{X} \pm \Delta)$

\begin{tabular}{|c|c|c|c|}
\hline \multirow[t]{2}{*}{ Control exercises } & \multicolumn{2}{|c|}{$\begin{array}{l}\text { Groups of } \\
\text { respondents }\end{array}$} & \\
\hline & $\begin{array}{c}\mathrm{CG}, \mathrm{n}= \\
12\end{array}$ & $\begin{array}{c}\text { EG, } n= \\
12\end{array}$ & \\
\hline 30 meters running, seconds & $\begin{array}{c}5,04 \pm 0 \\
13\end{array}$ & $\begin{array}{c}4,99 \pm 0 \\
12\end{array}$ & 0,05 \\
\hline 100 meters running, seconds & $\begin{array}{c}15,04 \pm 0 \\
, 42\end{array}$ & $\begin{array}{c}14,98 \pm 0 \\
, 32\end{array}$ & 0,05 \\
\hline 3000 meters running, seconds & $\begin{array}{c}795,4 \pm 1 \\
8,1\end{array}$ & $\begin{array}{c}793,2 \pm 1 \\
8,7\end{array}$ & 0,05 \\
\hline Standing long jump, $\mathrm{cm}$ & $\begin{array}{c}188,6 \pm 1 \\
0,9\end{array}$ & $\begin{array}{c}185,1 \pm 1 \\
1,1\end{array}$ & 0,05 \\
\hline chin-ups, times & $\begin{array}{c}10,6 \pm 0 \\
9\end{array}$ & $\begin{array}{c}10,9 \pm 1 \\
2\end{array}$ & 0,05 \\
\hline push-ups, times & $\begin{array}{c}48,7 \pm 4 \\
6\end{array}$ & $\begin{array}{c}45,2 \pm 5 \\
1\end{array}$ & 0,05 \\
\hline $\begin{array}{l}\text { Legs bringing to the barbell from hanging } \\
\text { position, times }\end{array}$ & $\begin{array}{c}10,2 \pm 1 \\
5\end{array}$ & $9,9 \pm 2,4$ & 0,05 \\
\hline Benchpress, kg & $\begin{array}{c}54,6 \pm 5 \\
8\end{array}$ & $\begin{array}{c}53,2 \pm 6 \\
7\end{array}$ & 0,05 \\
\hline
\end{tabular}


TABLE II. PHYSICAL READINESS INDICES AMONG SAMBO WRESTLERS AFTER THE FORMING PEDAGOGICAL EXPERIMENT

\begin{tabular}{|c|c|c|c|}
\hline \multirow{2}{*}{ Control exercises } & \multicolumn{2}{|c|}{$\begin{array}{l}\text { Groups } \\
\text { respondents }\end{array}$} & \\
\hline & $\begin{array}{l}\text { CG, } n= \\
12\end{array}$ & $\begin{array}{l}\mathrm{EG}, \mathrm{n}= \\
12\end{array}$ & \\
\hline 30 meters running, seconds & $\begin{array}{l}5,00 \pm 0,1 \\
1\end{array}$ & $\begin{array}{l}4,97 \pm 0,1 \\
2\end{array}$ & 0,0 \\
\hline 100 meters running, seconds & $\begin{array}{l}14,94 \pm 0 \\
40\end{array}$ & $\begin{array}{l}14,88 \pm 0, \\
32\end{array}$ & $\begin{array}{l}0,0 \\
5\end{array}$ \\
\hline 3000 meters running, seconds & $\begin{array}{l}782,4 \pm 1 \\
6,1\end{array}$ & $\begin{array}{l}763,2 \pm 1 \\
8,7\end{array}$ & 0,0 \\
\hline Standing long jump, $\mathrm{cm}$ & $\begin{array}{l}191,6 \pm 6 \\
7\end{array}$ & $\begin{array}{l}198,1 \pm 5 \\
1\end{array}$ & 00 \\
\hline chin-ups, times & $11,6 \pm 1,2$ & $12,9 \pm 1,4$ & 00 \\
\hline push-ups, times & $53,7 \pm 5,3$ & $59,2 \pm 4,7$ & 00 \\
\hline $\begin{array}{l}\text { Legs bringing to the barbell from hanging } \\
\text { position, times }\end{array}$ & $10,7 \pm 1,0$ & $\begin{array}{l}11,9 \pm 16 \\
4\end{array}$ & 00 \\
\hline Benchpress, kg & $58,6 \pm 3,8$ & $61,2 \pm 5,1$ & 00 \\
\hline
\end{tabular}

\section{CONCLUSION}

Comparative analysis of physical readiness indices, seen after the pedagogical experiment, showed that sambo wrestlers of the experimental group had comparatively valid results in test exercises, which characterize the level of general endurance, speed-power and strength oriented qualities development (table II).

For example, they had higher indices of 3000 meters running (763,2 against 782,4 sec. among sambo wrestlers from the control group).

They had validly better results in standing long jump (198,1 against 191,6 cm), in chin-ups (12,9 against 11,6 times), in push-ups (59,2 against 53,7 times), in legs bringing to the barbell from hanging position (11,9 against 10,7 times), in benchpress $(61,2$ against $58,6 \mathrm{~kg})$. These results prove experimental group respondents' advantage in the level of speed-power and strength oriented qualities development.

We think that observed by us valid advantage of sambo wrestlers from the experimental group after the pedagogical experiment in general endurance, speed-power and strength oriented indices development is conditioned by the use of created by us innovative methodology of physical qualities development in physical training of athletes.

\section{References}

[1] Bernshtein N. A. About dexterity and its development. Moscow: Physical culture and sport. 1991, 287.

[2] Bogen M. M. Teaching motor actions. Moscow: Physical culture and sport. 1985, 182.

[3] Gorodnichev R. M., Shlyakhtov V. N. Physiology of strength. Moscow: Sport. 2016, 227

[4] Eganov A. V. Methodology of initial training in judo: textbook for students of higher educational establishments and colleges. Chelyabinsk: Ural State University of Physical Culture. 2008, 283.

[5] Karelin A. A., Nelyubin V.V. About a rational succession of teaching wrestling technique. Problems of pedagogical activity in physical culture and sport and the ways of their solution in physical culture education: materials of scientific-practical conference of pedagogics department of P.F. Lesgaft Saint-Petersburg State Academy of Physical Culture, dedicated to A.A. Sidorov. Saint-Petersburg: NIIKSPbGU. 2002, 2, pp. 69-72.

[6] Kostychakov V.F. Playing technology of educational-training process of sambo wrestlers training activation. Candidate's thesis. Krasnoyarsk. 2006, 23.

[7] Kuptsov A. P. Sports wrestling. Moscow: Physical culture and sport. 1978, 58.

[8] Layshev R. A. Methodology of coordination of movements development among children, who go in for sambo wrestling. Candidate's thesis. Moscow. 1997, 24.

[9] Lents A. N. Sports wrestling. Moscow: Physical culture and sport. 1964, 240.

[10] Matveev L. P. General theory of sport and its applied aspects. SaintPetersburg: Lan. 2005, 384.

[11] Melchakov A. V. About wrestlers' coordination development. 2004. URL: http://www.krassport.ru.

[12] Piloyan R. A. A long-term training of athletes-combatants: manual. Malakhovka. 1999, 98.

[13] Platonov A. N. Qualified athletes training. Moscow: Physical culture and sport. 1986, 272.

[14] Romanov V. V. Sports selection methodology of sambo wrestlers at educational-training stage. Candidate's thesis. Moscow. 2006, 23.

[15] Rudman D. L. Sambo. - the $2^{\text {nd }}$ edition, transformed. Moscow: Physical culture and sport. 1985, 176.

[16] Gorodnichev R.M. Sambo: physiology essays: monograph. Velikie Luki. 2001, 147.

[17] Sambo: rules of competitions. All-Russian sambo federation. Moscow: Soviet sport. 2006, 128.

[18] Tabakov S.E., Eleseev S.V., Konakov V. Sambo: model program of sports training for sports schools for children and teen-agers, specialized sports schools for children and teen-agers of the Olympic reserve. Moscow: Soviet sport. 2005, 240.

[19] Stankov A. G. Individualization of wrestlers training: judo, sambo wrestling, freestyle wrestling and classical wrestling. Moscow. 1995, 240.

[20] Strategies of physical culture and sport development in the Russian Federation till 2020, adopted by the Government order of the Russian Federation on August, 7. 2009,1101-r.

[21] Tumanyan G. S. School of wrestlers', judo wrestlers' and sambo wrestlers' mastery: manual. Moscow: Academy. 2006, 592.

[22] [Federal Law "On physical culture and sport in the Russian Federation" on December, 4. 2007, 329-FZ, 39. URL: base.consultant.m/cons/cgi/online.cgi?req=doc;base=LAW;n=1 33423 .

[23] Aleksandr S. Kuznetsov, Evgeniya N. Usmanova, Oksana V. Kolomytseva. Athletes' psychological-physiological indices study in different specializations at the stages of sports career crises overcoming. Russian Journal of Physical Education and Sport. 2019, 14(2), pp. 75-81. DOI: 10.14526/2070-4798-2019-14-2-89-96.

[24] Kuznetsova Z.M., Kuznetsov S.A., Ovchinnikov Yu. D., Golovko P.V. Analysis of the morphological-functional indices connection degree in throwing among athletes. The Russian Journal of Physical Education and Sport. 2018, 13(2), pp. 44-51. DOI: 10.14526/02_2018_308. 